\title{
Recognition and Recall in Low Birth Weight Infants
}

\author{
Miriam Ittyerah* and Anuradha Mangapalli
}

Department of Psychology, Christ University, Bangalore- 560029, India

\begin{abstract}
Cognitive abilities of low birth weight infants (1500-2000 grams) were compared to that of normal controls (2500-3500 grams) in tasks using recognition and recall measures. Three groups of infants at different ages: group I (4-6 months), group II (7-9 months), and group III (10-12 months), each consisting of 30 low birth weight and 30 controls participated in the study.

Infants of group I were tested for fundamental sensory abilities such as visual recognition memory, auditory and tactile preferences. Infants of group II were tested on tasks of imitation and object permanence, both requiring some form of representation and recall abilities. Infants of group III were tested on inter-modal matching, which required ability for sensory integration.

Results indicate that the low birth weight infants performed poorly on all tasks except tactile preferences. They seem to lag behind the normal infants in general, and in some tasks by approximately four weeks. This suggests the importance of brain maturation for the performance of these tasks since previous studies indicate a relationship between birth weight and cognitive performance. Thus intra-uterine growth retardation (IGUR) consequently delays development and is an important determinant of low birth weight.
\end{abstract}

Key Words: Low birth weight, IGUR, infants, cognition.

\section{INTRODUCTION}

Infants weighing less than 2500 grams at birth are defined as low birth weight (LBW) babies (WHO, 1961), though most medical centers in India use 2000 grams or less as criteria for low birth weight [1]. The chances of survival for these infants have increased in the past years owing to technological advances in prenatal and perinatal care. However concern has been expressed over the quality of the survivors and their developmental outcome. Cognitive deficits, learning disorders, behavior problems and poor school behaviours have been often associated with low birth weight [2-4] suggests that LBW is a useful vulnerability marker for early drug use among boys independent of antecedents or sequelae of LBW. Research [5] also indicates that LBW is an independent risk factor for attention-deficit hyperactivity disorder (ADHD).

Most studies with infants at risk need to be reevaluated, since preterm infants not small for gestational age (SGA) are often referred to as low birth weight infants [6], though the clinical problems and prognosis of both are quite different. The rates of LBW vary according to both ethnicity and country. In affluent societies such as the United States, preterm birth is the principal determinant of LBW [7]. In developing countries, however, LBW is commonly related to intrauterine growth retardation (IUGR). LBW births account for roughly 6 to $6.9 \%$ of all live births [8]. Among developed countries, the United States has an unusually high rate of $\mathrm{LBW}$, though this high rate cannot be attributed solely to

*Address correspondence to this author at the Department of Psychology, Christ University, Bangalore- 560029, India;

E-mail: miriamittyerah7@yahoo.co.in racial differences [7]. In India, about one third of the infants are small for date [9]. The etiology of preterm birth and IGUR has been associated with several risk factors such as maternal health or social and economic conditions, though for the most part factors associated with preterm birth are related to reproductive history and the infants are not necessarily LBW, whereas factors associated with IGUR are usually demographic [10]. While measures used in these studies are often general and usually test only the visual modality, or subsequently conclude that the neurobehavioual sequelae of LBW are confined to the visual-motor domain [11], some others have suggested deficits for verbal and nonverbal domains in post linguistic children [12]. Therefore other sources of information about infants' cognitive abilities are relatively less investigated. In the present study, it is of interest to know and review the cognitive abilities of low birth weight infants in some of the fundamental sensory modalities and motor behaviours that sustain development. The study differs from previous studies in that the group tested is specified, that is, small for gestational age (SGA), and free of birth complications. Their birth weight ranged from 1500 grams to 2000 grams and the length of gestation from 39 to 42 weeks. Infants born premature were excluded all together. Infants selected as controls were appropriate for gestational age (AGA). Their length of gestation was the same as those of SGA, though their birth weight ranged from 2500-3500 grams. Both groups of infants were tested on tasks thought to be indicative of later intelligence.

\section{Intrauterine Growth Retardation -IUGR}

Intrauterine growth retardation -IUGR- is a clinical entity in which the fetus does not grow appropriately in the uterus 
because of unfavorable factors operating during pregnancy. The broad hypothesis generated is that early malnutrition including prenatal malnutrition retards brain growth and that the brain's organic deficit in turn leads to mental deficits. It was therefore hypothesized that the low birth weight infants will differ from their normal controls in tests of sensory processing, deferred imitation, object concept and inter modal perceptual abilities, for the reasons already explained and show differences in development.

\section{METHOD}

\section{Subjects}

The infants selected for the study were from three age groups: group I (4-6 months), group II (7-9 months), group III (10-12 months) each consisting of 30 low birth weight infants and 30 normal controls. The infants were recruited from the birth register of a local hospital (Deen Dayal Upadhyay Hospital) situated in West Delhi. The lbw were full term, small for gestational age. The mean birth weight of the lbw was 1700 grams, standard deviation of 800 grams and mean length of gestation was 40 weeks. The mean birth weight of the normal infants was 3000 grams, standard deviation of 500 grams and their mean length of gestation was 40 weeks. At the time of the study all infants lived at home. Both the groups were matched approximately at each age level for sex, length of gestation, level of education of parents and socio-economic status in general.

\section{Part 1 - Visual Recognition Memory}

One method, much employed by researchers in investigating infant memory is the habituation-dishabituation paradigm first introduced by Fantz (1958) [13]. It is of interest in the present study to know if low birth weight has a detrimental effect on tests of visual preference and habituation, which are considered to be predictive of some measures of intelligence.

\section{Stimuli}

Four two dimensional visual stimuli painted on white cardboard (10x 8 inches). (1) Green and red circles, $15 \mathrm{~cm}$. in diameter. (2) Two blue colored stimuli of same intensity differing in form (one cylindrical $16.7 \mathrm{~cm}$ in length and 7.5 $\mathrm{cm}$. in breadth and another diamond shaped $13 \mathrm{~cm}$ in length and $10.2 \mathrm{~cm}$ in width). (3) Two checker boards, one $6 \times 6$ with one inch-square checks and the other $12 \times 12$ with half inch square checks. (4) Two photographs of faces of women with neutral expression.

\section{Procedure}

The procedure was kept the same for both groups of infants. All the infants were observed at their homes by means of a visual preference apparatus at a time when they were judged to be alert and contended. The infants were held by their mothers in their laps while facing the screen at a distance of approximately 18 inches. The stimulus presentation technique was similar to that of Fagan (1971) [14] in which two identical targets are presented side by side for a familiarization period of one minute, immediately followed by two 30 seconds testing periods in which the now familiar stimulus is paired in alternate right and left positions, with the novel stimulus. The order of presentation of the stimuli was counter balanced.

\section{Scoring}

Looking times on test trials were noted. On an average, infants spent five to eight seconds on familiar stimuli in test trials. Very soon they would revert their gaze to the novel stimulus and spend longer time looking at it and hence only the latter were scored. There were a total of 6 trials per task. The mean looking time of each infant for 6 trials was recorded. In all, for 30 low birth weight infants there were $6 \times 30=180$ trials for one task. Thus for four tasks there were $4 \times 180=720$ preference trials for the low birth weight group. The normal controls were also scored in the same way.

A similar procedure and scoring was followed for the auditory and tactile preferences.

\section{Auditory Perception}

\section{Stimuli}

(1) A rattle, (2) buzzer, (3) an audiocassette, (4) motherese.

The stimuli were presented to the left and right ears of the infants and scored for attending time.

\section{Tactile Perception}

\section{Stimuli}

(1) A small plastic ball (size $4 \mathrm{~cm})$, (2) a cylindrical plastic dowel (14 cm long and $1.5 \mathrm{~cm}$ wide, (3) a soft to touch purse made of fur.

The stimuli were given to the infants to be held in their hands and scored in terms of holding times.

\section{RESULTS}

\section{Visual Recognition Memory, Auditory and Tactile Pref- erences}

The mean responses times and s. d. are presented in Tables $\mathbf{1}, \mathbf{2}$ and $\mathbf{3}$. The tables indicate that the normal infants had longer response times as compared to that of the lbw infants.

The ANOVA results for visual recognition indicate that the groups $\left[\mathrm{F}_{(1,54)}=6.3,{ }_{\mathrm{P}}<.05\right]$, age $\left[\mathrm{F}_{(2.54)}=19.88,{ }_{\mathrm{P}}<\right.$ $.01]$ and task were significant $\left[\mathrm{F}_{(3,162)}=37.35,{ }_{\mathrm{P}}<.01\right]$. Tukey's post-hoc tests showed that the four treatments differed. Complex patterns were preferred to forms $(265, \mathrm{p}<$ $.01)$ and photographs $(114.3, \mathrm{p}<.01)$. The age $\mathrm{x}$ task interaction was significant $\left[\mathrm{F}_{(6,162)}=54.85, \mathrm{p}<.01\right]$. Newman Keul's, post hoc (simple effects) tests, showed that four months old infants $\left[\mathrm{F}_{(6,162)}=28.53, \mathrm{P}_{\mathrm{P}}<.05\right]$ looked more at color and forms than complex patterns and photographs. 5 months old infants $\left[\mathrm{F}_{(6,162)}=24.87, \mathrm{p}<.01\right]$ preferred color most, to be followed by complex patterns, forms and photographs. The 6-month-old infants $\left[\mathrm{F}_{(6,162)}=72.63, \mathrm{P}<.05\right]$ looked longer at complex patterns and photographs than color and forms.

Anova for auditory preferences showed that the normal controls were more attentive than the low birth weight infants $\left[F_{(1,54)}=5.17,{ }_{P}<.05\right]$. The main effect of age $(B)$ was significant $\left[\mathrm{F}_{(2,54)}=23.62, \mathrm{P}<.01\right]$ indicating greater atten- 
Table 1. Visual Preferences

\begin{tabular}{|c|c|c|c|c|c|c|c|c|}
\hline & \multicolumn{4}{|c|}{ Normal } & \multicolumn{4}{|c|}{ Low Birth Weight } \\
\hline & C1 & $\mathrm{C} 2$ & $\mathbf{C 3}$ & $\mathrm{C4}$ & C1 & $\mathrm{C2}$ & $\mathbf{C 3}$ & $\mathrm{C4}$ \\
\hline \multicolumn{9}{|l|}{$4 \mathrm{mo}$} \\
\hline SD & 3.47 & 4.17 & 4.33 & 3.61 & 3.67 & 3.5 & 6.12 & 3.50 \\
\hline \multicolumn{9}{|l|}{$5 \mathrm{mo}$} \\
\hline Mean & 22.78 & 24.44 & 17.51 & 20.15 & 19.66 & 20.37 & 14.47 & 15.38 \\
\hline SD & 6.92 & 10.1 & 5.0 & 4.64 & 7.52 & 9.14 & 5.97 & 4.28 \\
\hline SD & 10.36 & 7.09 & 3.51 & 7.05 & 9.37 & 6.5 & 3.34 & 7.03 \\
\hline
\end{tabular}

$\mathrm{C} 1=$ Complex patterns, $\mathrm{C} 2=$ Color, $\mathrm{C} 3=$ Forms, $\mathrm{C} 4=$ Photographs, mo=months.

Table 2. Auditory Preferences

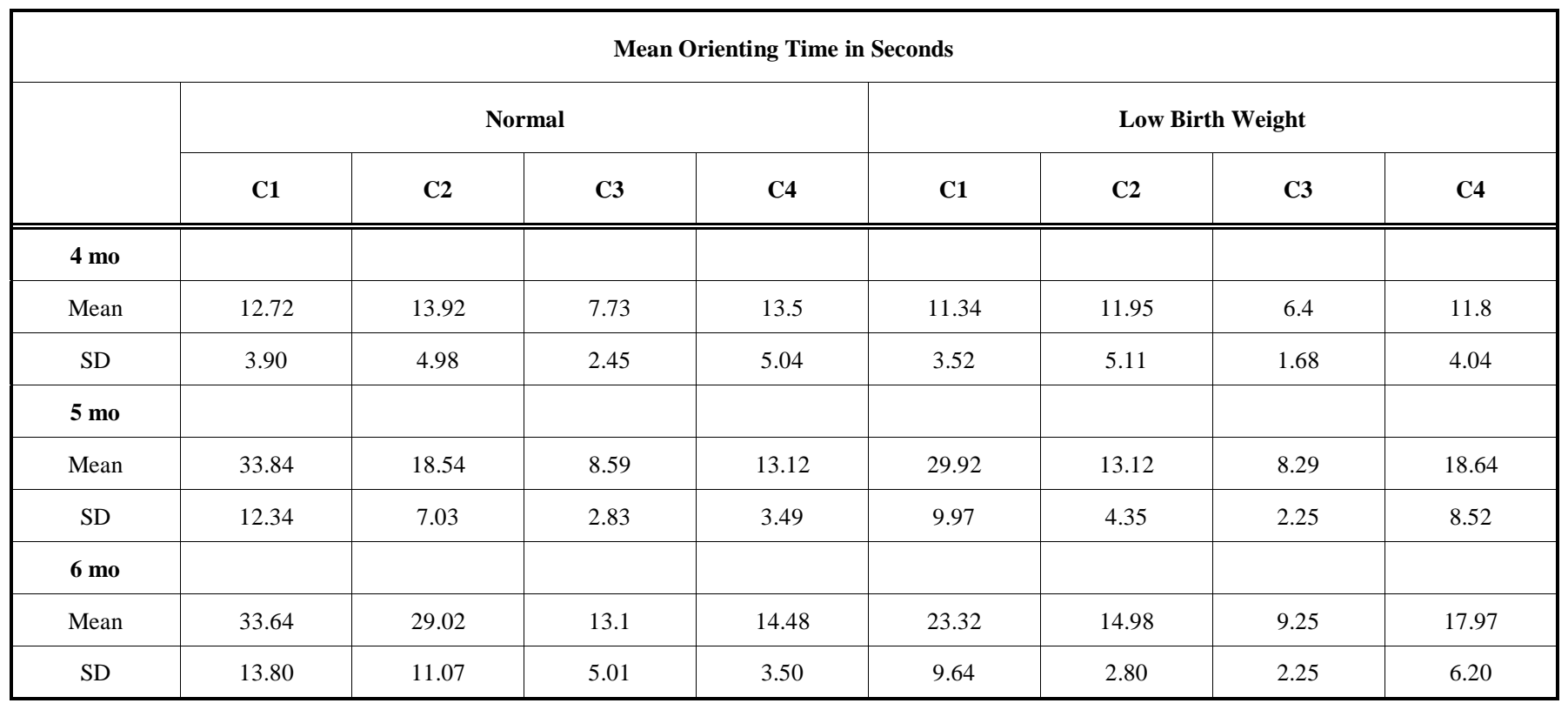

$\mathrm{C} 1=$ Motherese, $\mathrm{C} 2=$ Buzzer, $\mathrm{C} 3=$ Music, $\mathrm{C} 4=$ Rattle. $\mathrm{Mo}=$ months .

tion in older infants. The main effect of task was significant $\left[\mathrm{F}_{(3,162)}=16.25, \mathrm{p}<.01\right]$. Tukey's post-hoc tests showed that infants both normal and low birth weight showed greater preference for motherese as compared to music $\left(961, \mathrm{p}_{\mathrm{p}}<.01\right)$ and buzzer $\left(482, \mathrm{p}_{\mathrm{p}}<.01\right)$ and rattle sounds $(352, \mathrm{p}<.01)$, respectively. The age $\mathrm{x}$ task interaction was significant $\left[\mathrm{F}_{(6}\right.$, $\left.{ }_{162)}=2.76,{ }_{\mathrm{P}}<.05\right]$. Newman Keul's post hoc tests showed that the age of the infants influenced their performance on all the tasks. Buzzer sounds seemed to elicit the earliest differential response in the 4-month-old infants only to be followed by motherese and rattle sounds $\left[\mathrm{F}_{(6,162)}=8.95\right.$, $\mathrm{p}<$ $.05]$. The 5 months old $\left[\mathrm{F}_{(6,162)}=113.02, \mathrm{p}<.05\right]$ and 6 months old $\left[\mathrm{F}_{(6,162)}=63.48, \mathrm{P}_{\mathrm{P}}<.05\right]$ infants preferred motherese to rattle and music.

For tactile preferences only the main effect of age was significant $\left[\mathrm{F}_{(2,54)}=32.19, \mathrm{P}_{\mathrm{P}}<.01\right]$. There were neither group nor task differences.

\section{Part II - Imitation}

\section{Stimuli}

(1) A plastic duck. (2) Two cubes red in color (size $2.5 \times 2.5$ inches). (3) Steel bowl with a spoon. (4) A hat made of lightweight plastic. 
Table 3. Tactile Preferences

\begin{tabular}{|c|c|c|c|c|c|c|}
\hline \multicolumn{7}{|c|}{ Mean Holding Time in Seconds } \\
\hline & \multicolumn{3}{|c|}{ Normal } & \multicolumn{3}{|c|}{ Low Birth Weight } \\
\hline \multicolumn{7}{|l|}{$4 \mathrm{mo}$} \\
\hline \multicolumn{7}{|l|}{$5 \mathrm{mo}$} \\
\hline Mean & 18.16 & 17.62 & 17.28 & 16.88 & 16.59 & 16.27 \\
\hline $\mathrm{SD}$ & 6.37 & 3.77 & 5.8 & 5.93 & 3.53 & 5.79 \\
\hline
\end{tabular}

$\mathrm{C} 1=$ Purse, $\mathrm{C} 2=\mathrm{Ball}, \mathrm{C} 3=$ Dowel, $\mathrm{mo}=$ months.

\section{Procedure}

The experimenter sat facing the infant at a distance of approximately 12 inches. The experimenter modeled the tasks to the infant one by one, with an interval of 30 seconds between the tasks. The actions modeled for imitation were four visible actions involving performance with objects such that the infant could observe his/her own imitation. The specific procedures for these modeled actions are presented below:

1. Stack Cubes: The experimenter made available two, two and a half inch red cubes. Using two cubes, she placed one atop the other.

2. Squeezes duck: A red and yellow soft plastic duck was placed before the infant. The experimenter held the duck by the neck and squeezed it several times to produce a sound.

3. Stirs with a spoon: A metal (steel) bowl and a spoon were placed before the infant. The experimenter made stirring movements inside the cup making loud noise.
4. Placing the hat: The experimenter placed a white lightweight plastic hat before the child. The experimenter lifted the hat slowly and placed it on her head.

After a 15 minutes delay the infants were given the stimulus materials one by one, each for a period of $60 \mathrm{sec}-$ onds, and observed to test if they could repeat what they had seen. To isolate imitative responding from chance, two control groups consisting of 30 infants in each group, one for the low birth weight infants and another for the normal infants were required to participate. The control groups did not see the target action. Without such controls, it would be difficult to know whether the behavior produced was by chance or an imitative act.

\section{Results}

The mean performance is presented in Table 4.

The table indicates that the normal infants scored high on imitation tasks as compared to the low birth weight infants.

Table 4. The Mean Performance

\begin{tabular}{|c|c|c|c|}
\hline Age in months & Mean and SD & Normal & Lbw \\
\hline \multirow{2}{*}{$7 \mathrm{mo}$} & Mean & 2.90 & 2.50 \\
\hline & $\mathrm{SD}$ & 0.83 & 0.50 \\
\hline \multirow{2}{*}{$9 \mathrm{mo}$} & Mean & 5.50 & 4.40 \\
\hline & SD & 1.11 & 0.91 \\
\hline
\end{tabular}

mo $=$ months . 
The anova results indicate that the low birth weight infants differed from the normal controls on imitation tasks [F $\left.(1,54)=38.5,{ }_{\mathrm{P}}<.01\right]$. The main effect of age was significant $\left.\left[\mathrm{F}_{(2,54)},=93.88, \mathrm{p}<.01\right)\right]$ showing developmental differences with age. The group $x$ age interaction was significant $\left[F_{(2,54)}\right.$ $=3.98, \mathrm{p}<.05]$. Newman Keul's post hoc tests showed that the birth weight did have an effect on their performance at different ages i. e., for the normal controls $\left[\mathrm{F}_{(2,54)}=126.18\right.$, $\mathrm{p}<.05]$ and the low birth weight infants $\left[\mathrm{F}_{(2,54)}=66.92, \mathrm{p}<\right.$ $.05]$. The scores of 9 months old low birth weight infants seem to match that of 8-month-old normal infants suggesting that the former lag behind the latter by approximately 4 weeks.

\section{Object Concept}

Stimuli: (1) A cardboard 2.5 feet long and one foot wide. (2) Two off white towels $24 \times 24 \mathrm{~cm}$. (3) One green and one pink towel $(24 \times 24 \mathrm{~cm})$. (4) A flat attractive key chain.

\section{Procedure}

All the infants were tested when judged to be alert and in good condition. They were seated comfortably on a mat or a center table or held by their mothers or caregivers in their laps. Two positions A and B were marked one foot apart on the board. A flat key chain was placed at position A and the infant was allowed to pick it up. Two warm up trials and three test trials at A and five test trials at position B were given for both conditions. In one condition two same colored covers (off white $24 \times 24 \mathrm{~cm}$.) were used to cover the object at positions A and B. In condition two, two different colored covers one green and one pink were used to cover the object at different positions.

Infants had little difficulty in retrieving the object from position A, whether the color of the cover was same or different. Only search at B was scored. If the infant retrieved the object from $\mathrm{B}$ s/he was given a score of 2 . If s/he placed his hand at the right place i.e. at $\mathrm{B}$ a score of one was awarded. If searched incorrectly i.e. at A, a score of zero was given. The score were averaged over 5 trials. The maximum possible score was ten and the minimum was zero.

\section{Results}

The mean performance of the infants is presented in Table 5.

The table shows that the low birth weight infants have more error than the controls.

The anova results indicate that the normal controls made fewer errors on search tasks compared to low birth weight infants $\left[\mathrm{F}_{(1,54)}=20.42,{ }_{\mathrm{P}}<.01\right]$. The main effect of age (B) was significant $\left[\mathrm{F}_{(2,54)}=29.92, \mathrm{P}_{\mathrm{P}}<.01\right]$. The main effect of the experimental condition was significant $\left[\mathrm{F}_{(1,54)}=49.6\right.$, $\mathrm{P}$ $<.01]$ showing that the infants made more errors when the color of the cloth covers was same. The age $\mathrm{x}$ task interaction was significant $\left[\mathrm{F}_{(1,54)}=3.35, \mathrm{P}_{\mathrm{P}}<.05\right]$. The number of errors made by the infants seemed to differ with age, i.e. at 7 months $\left[\mathrm{F}_{(2,54)}=5.25,{ }_{\mathrm{P}}<.01\right], 8$ months $\left[\mathrm{F}_{(2,54)}=13.8,{ }_{\mathrm{P}}<\right.$ $.01]$ and 9 months $\left[\mathrm{F}_{(2,54)}=24.5,{ }_{\mathrm{P}}<.01\right]$. Younger infants made more errors.

\section{Part 3 - Inter-Modal Perception}

\section{Stimuli}

Live models participated. A male graduate student 21 years old and a female graduate student 23 years served as models in the experiment.

\section{Procedure}

The infants were seated comfortably in an infant seat or held by their mothers or their caretakers in their lap while facing the experimental set up. The male model was made to sit in the chair facing the infant. After smiling at the infant for several seconds he began to talk softly to the infant. The time (in seconds) the infant attends to the model was recorded. The procedure was repeated with a female model. In the third step the male model makes lip movements while the female model talks from behind the screen. Alternatively the female model makes lip movements while the male model talks from behind the screen. The dependent measure was the total amount of time the infant spends looking at the models. The presentation orders of the male and female

Table 5. Object Permanence

\begin{tabular}{|c|c|c|c|c|c|}
\hline \multirow{2}{*}{ Age in months } & \multirow{2}{*}{ Mean and SD } & \multicolumn{2}{|c|}{$\mathrm{C} 1$} & \multicolumn{2}{|c|}{$\mathrm{C} 2$} \\
\hline & & Lbw & Normal & Lbw & Normal \\
\hline $7 \mathrm{mo}$ & Mean & 4.00 & 3.60 & 3.20 & 2.95 \\
\hline \multirow{2}{*}{$8 \mathrm{mo}$} & Mean & 3.40 & 2.85 & 2.65 & 2.15 \\
\hline & SD & 0.70 & 0.67 & 0.59 & 0.22 \\
\hline \multirow{2}{*}{$9 \mathrm{mo}$} & Mean & 2.90 & 2.15 & 2.55 & 1.95 \\
\hline & SD & 0.66 & 0.45 & 0.41 & 0.26 \\
\hline
\end{tabular}

$\mathrm{C} 1=$ Experimental condition in which the color of the cloth covers is same and $\mathrm{C} 2=$ Experimental condition in which the color of the cloth covers is different, mo=months. 
models with and without their corresponding voice sounds were counterbalanced over the trials.

\section{Results} 6.

The mean performance of the infants is presented in Table

The table indicates that the normal infants showed greater attention than the low birth weight infants. The anova results showed that the main effect of group was significant $\left[\mathrm{F}_{(1,54)}=15.88,{ }_{\mathrm{P}}<.01\right]$. The main effect of age was significant $\left[\mathrm{F}_{(2,54)}=98.34, \mathrm{P}<.01\right]$ showing developmental differences with age. The means indicate that the looking times increased with age. The group $\mathrm{x}$ age interaction was significant $\left[\mathrm{F}_{(2,54)}=6.82, \mathrm{P}<.01\right]$. Post hoc tests (simple effects) showed that the normal infants $\left[\mathrm{F}_{(2,54)}=127.12, \mathrm{P}<.01\right]$ and low birth weight infants $\left[\mathrm{F}_{(2,54)}=83.11, \mathrm{p}<.01\right]$ differed significantly on tasks. The main effect of the task was significant $\left[\mathrm{F}_{(3,162)}=23.05, \mathrm{P}_{\mathrm{P}}<.01\right]$. Tukey's post hoc tests indicated that the four treatments differed. The infants preferred to look more at the male face, male voice than at a female face paired with male voice $(258.2, \mathrm{P}<.01]$, or at the male face paired with female voice $(179.4, \mathrm{P}<.01]$.

\section{Experimenter Bias and Inter Observer Reliability}

A fellow researcher not aware of the groups assisted the experimenter in conducting the experiments to control for experimenter bias. Cohen's Kappa [15] indicate that the inter rater reliability between the experimenter and the researcher was high for visual preference (.9), for auditory preference (.89), for tactile preference (.92), for imitation (.94), for object permanence (.95) and for inter modal matching (.91).

\section{DISCUSSION}

Most studies conducted on LBW infants indicate a relationship between birth weight and cognitive and/or social development. The consensus is that the low birth weight is associated with neuropsychological [8], behavioral [16] and psychiatric [12] sequelae.

Most research however has focused on outcomes in school going populations $[17,18]$. Studies on infants especially of those below two years is sparse and even the ones that exist have used traditional assessment tools which have not proven to be very good predictors of later intelligence [19]. In the present study, low birth weight infants performed poorly on both visual and auditory preferences. However their performance on tactile preferences did not differ from the normal infants. There seems to be some developmental progression in the preferences of infants. The low birth weight infants though they performed better than might have been expected, did not show a reliable novelty response until a later age than that of the NBW. Developmental differences indicate that performance improves with age and cannot be attributed to delay in tactile/motor abilities.

The low birth weight infants seem to lag behind the NBW in cognitive development. They displayed lower attention on visual and auditory tasks, delayed novelty response, and were less able on representation and recall measures and cross modal tasks. A developmental difference of about four weeks was found for most tasks, showing that the LBW infants seem to differ from those born appropriate for gestational age in various developmental domains. Thus IUGR as a determinant of LBW and subsequent development is an indication of the state of the mother's health and nutrition during pregnancy. IGUR has an impact on the brain development of the fetus since every mode of sensory experience except vision is active in the fetus during the last trimester of human pregnancy [20]. Hence the need for maternal care is imperative for the prevention of LBW.

\section{ACKNOWLEDGEMENTS}

The authours wish to thank the infants and parents for their patience and interest all through the study. We also

Table 6. Intermodal Perception

\begin{tabular}{|c|c|c|c|c|c|c|c|c|}
\hline \multicolumn{9}{|c|}{ Mean Looking Times in Seconds } \\
\hline & \multicolumn{4}{|c|}{ Normal } & \multicolumn{4}{|c|}{ Low birth weight } \\
\hline \multicolumn{9}{|l|}{$10 \mathrm{mo}$} \\
\hline SD & 2.65 & 3.8 & 2.23 & 3.03 & 2.25 & 2.67 & 1.12 & 2.33 \\
\hline \multicolumn{9}{|l|}{$11 \mathrm{mo}$} \\
\hline Mean & 15.49 & 16.17 & 10.44 & 12.53 & 14.87 & 15.93 & 11.87 & 12.17 \\
\hline SD & 5.87 & 5.68 & 2.30 & 4.10 & 3.72 & 3.69 & 3.46 & 3.55 \\
\hline SD & 7.19 & 6.12 & 3.55 & 3.38 & 4.96 & 3.62 & 3.88 & 3.46 \\
\hline
\end{tabular}

$\mathrm{C} 1=$ Female face, female voice; $\mathrm{C} 2=$ Male face male voice; $\mathrm{C} 3=$ Female face, male voice; Male face, female voice, mo= months. 
acknowledge with gratitude the assistance of family and friends during data collection.

\section{REFERENCES}

[1] Bhargava V, Ghose S, Bhargava SK. Survival, growth and development in babies weighing 2000gms or less. Indian Pediatr 1974; 7: 3 .

[2] Grunau RE, Whitefield MF, Davis C. Pattern of learning disabilities in children with extremely low birth weight and broadly average intelligence. Arch Pediatr Adolesc Med 2002; 156: 615-20.

[3] Breslau N, Chilcoat HD, Johnson EO, Andreski VC. Neurological soft signs and low birth weight; their association and neuro psychiatric implications. Biol Psychiatry 2000; 47: 71-9.

[4] Chilcoat HD, Breslau N. Low birth weight as a vulnerability marker for early drug use. Exp Clin Psychopharmacol 2002; 10: 104-12.

[5] Mick E, Biederman J, Prince J, Fischer MJ, Faraone SV. Impact of low birth weight on attention-deficit hyperactivity disorder. J Dev Behav Pediatr 2002; 23: 16-22.

[6] Leonard CM, Piecuch RE, Cooper BA. Use of the Bayley infant Neurodevelopmental Screener with low birth weight infants. J Pediatr Psychol 2001; 26: 33-40.

[7] Paneth NS. The problem of low birth weight. Future Child 1995; 5: 19-34.

[8] Picard EM, DelDotto JE, Breslau N. Prematurity and low birth weight. In: Yeates KO, Douglas M, Taylor HG, Eds. Pediatric Neuropsychology: Research, theory and practice. The Guilford Press; New York, 2000.

[9] Sharma A. LBW in Indian infants. Reviews and comments. Nutrition Foundation of India. Bull 2002.
[10] Kramer MS. Determinants of low birth weight: Methodological assessment and meta-analysis. Bull World Health Organ 1987; 65 (5): 663-737.

[11] Rickards AL, Kitchen WH, Doyle LW, Ford FG, Kelly EA. Callanan C. Cognition, school performance and behaviour in very low birth weight and normal birth weight children at 8 years of age: A longitudinal study. J Dev Behav Pediatr 1993; 14: 363-8.

[12] Breslau N, Chilcoat H, Del Dotto JE, Andreski P. Brown G. Low birth weight and neurocognitive status at six years of age. Biol Psychiatry 1996; 40: 386-97.

[13] Fantz R Z. Pattern vision in young infants. Psychol Rec 1958; 8: 43-7.

[14] Fagan JF. Infants recognition memory for a series of visual stimuli. J Exp Child Psychol 1971; 11: 244-50

[15] Siegel S, Castellan JN Jr. Non parametric statistics for the behavioural sciences. $2^{\text {nd }}$ ed. New York: McGraw-Hill, 1988.

[16] Sykes DH, Hoy EA, Bill JM, McLure BG, Halliday HL, Mark MR. Behavioral adjustment in school of very low birth weight children. J Child Psychol Psychiatry 1997; 38: 315-25.

[17] Hack M, Klein N, Taylor HG. School-age outcomes of children of extremely low birth weight and gestational age. Semin Neonatol 1996; 1: 1-12.

[18] Dewey D, Crawford SG, Creighton DE, Sauve RS. Long term neuropsychological outcomes in very low birth weight children free of sensori-neural impairments. J Clin Exp Neuropsychol 1999; 21: 851-65.

[19] Pryor J. Physical and behavioral correlates of 12months development in small-gestational age and appropriately grown infants. J Reprod Infant Psychol 1996; 14: 233-42.

[20] Busnel MC, Granier-Deferre C, Lecanuet JP. Fetal audition. Ann N Y Acad Sci 1992; 662: 118-34. 